DR AHMED AL-SAMADI (Orcid ID : 0000-0003-1938-2136)

Article type : Original Article

\title{
Immune Checkpoints Indoleamine 2,3-Dioxygenase 1 and Programmed Death-Ligand 1 in Oral Mucosal Dysplasia
}

Meri Sieviläinen $^{1 *}$, Fabricio Passador-Santos ${ }^{2 *}$, Rabeia Almahmoudi ${ }^{1}$, Solomon Christopher ${ }^{3}$, Maria Siponen ${ }^{4,5}$, Sanna Toppila-Salmi ${ }^{6}$, Tuula Salo ${ }^{1,7,8 \#}$, Ahmed Al-Samadi ${ }^{1 \# \S}$

${ }^{1}$ Department of Oral and Maxillofacial Diseases, Clinicum, University of Helsinki, Helsinki, Finland.

${ }^{2}$ Department of Pathology, São Leopoldo Mandic Research Centre, Campinas, Brazil.

${ }^{3}$ Department of Mathematics and Statistics, University of Helsinki, Helsinki, Finland.

${ }^{4}$ Department of Oral and Maxillofacial Diseases, Kuopio University Hospital, Kuopio, Finland.

${ }^{5}$ Institute of Dentistry, University of Eastern Finland, Kuopio, Finland.

${ }^{6}$ Department of Allergy, University of Helsinki and Helsinki University Hospital, Helsinki, Finland

${ }^{7}$ Medical Research Centre, Oulu University Hospital, Oulu, Finland

${ }^{8}$ Department of Diagnostics and Oral Medicine, Research Group of Cancer Research and Translational Medicine, Medical Faculty, University of Oulu, Oulu, Finland

This article has been accepted for publication and undergone full peer review but has not been through the copyediting, typesetting, pagination and proofreading process, which may lead to differences between this version and the Version of Record. Please cite this article as doi: 10.1111 /jop. 12737

This article is protected by copyright. All rights reserved. 
Financial support. The authors acknowledge the funders of this study: the Sigrid Jusélius Foundation, cancer society of Finland, the Oulu University Hospital MRC grant, the Emil Aaltonen Foundation, the Helsinki University Central Hospital research funds, Eteläsuomalaisten ylioppilaiden säätiö, Helsingin seudun hammaslääkärit, and the Finnish Dental Society Apollonia.

Contact information. Ahmed Al-Samadi, Department of Oral and Maxillofacial Diseases, Clinicum, Biomedicum Helsinki 1, C223b P.O. Box 63 (Haartmaninkatu 8), 00014 University of Helsinki, Helsinki, Finland. Tel: +358458947224, Email: ahmed.alsamadi@helsinki.

Conflict of interest disclosure statement. The authors declare no potential conflicts of interest with respect to the authorship and/or publication of this article.

* The authors contributed equally to this work

\# The authors contributed equally to this work

$\S$ Corresponding author

Running title: Immune Checkpoints in Oral Mucosal Dysplasia

Keywords: IDO1; PD-L1; oral dysplasia; immune checkpoint; potentially malignant lesion. 


\begin{abstract}
Background: Oral mucosal dysplasia is a histologic feature of potentially malignant disorders that is associated with risk of transformation to carcinoma. Dysplastic cells use many strategies during their transformation to cancer, including escape from the immune mediated destruction. We hypothesized that adaptive immunity is inhibited by activation of distinct immune checkpoint molecules, such as indoleamine 2,3-dioxygenase 1 (IDO1) and programmed death-ligand 1 (PD-L1).
\end{abstract}

Methods: We collected 63 oral dysplasia samples from 47 patients. Nine biopsies from alveolar mucosa during wisdom teeth extractions were used as healthy controls. Tissue samples were stained and scored for IDO1 and PD-L1. Additionally, dysplasia grades and inflammatory cell infiltration were evaluated. Eight patients were followed up to 36 months to evaluate dysplasia progression, inflammation, and immune checkpoint molecule expression.

Results: Dysplastic epithelium had significantly lower IDO1 expression than that of healthy controls. PD-L1 positive cells in the lamina propria were mainly in dysplastic samples and seldom in healthy controls. Dysplasia grade associated negatively with epithelium IDO1 and positively with IDO1 and PD-L1 expression in the lamina propria. There was a positive association between dysplasia grade and level of inflammatory cell infiltration. During follow-up, dysplasia grade, inflammatory cell infiltration, and the immune checkpoint expression fluctuated over time.

Conclusions: Immune checkpoint molecules IDO1 and PD-L1 are modulated during oral epithelial dysplastic changes and their expression is associated with inflammatory cell infiltration in the lamina propria. As immune checkpoint molecule expression fluctuates over time, these molecules are not useful as biomarkers for oral mucosal dysplasia progression.

This article is protected by copyright. All rights reserved. 


\section{INTRODUCTION}

Oral dysplasia is a histologic feature of potentially malignant disorders characterized by loss of uniformity of individual epithelial cells and their architectural orientation. Dysplastic changes include pleomorphism, hyperchromatic nuclei, abnormally large cell size, abundant mitotic figure accumulation, and loss of progressive maturation of basal cells ${ }^{1}$. Oral dysplasia has a significant transformation risk to oral squamous cell cancer ${ }^{2}$. In a recent meta-analysis, it was estimated that oral dysplasia has an overall $10.5 \%$ malignant transformation risk ${ }^{2}$. However, several studies showed a wide range $(5-27 \%)$ of transformation risks, mainly depending on dysplasia grade ${ }^{3-6}$. It is believed that during malignant transformation, the dysplastic cells may escape from destruction mediated by the adaptive immune system ${ }^{7}$.

Immune checkpoints refer to a group of molecules that induce immune tolerance, prevent induction of autoimmune diseases, and protect tissues from immune collateral damage ${ }^{8}$. Immune checkpoints are used by cancer cells to escape from immune cell destruction, mainly by $\mathrm{CD}^{+} \mathrm{T}$ cells and NK cells ${ }^{9}$. The presence of distinct immune checkpoint molecules, such as indoleamine 2,3-dioxygenase 1 (IDO1) and programmed death-ligand 1 (PD-L1) in tumors, are considered as negative prognostic factors ${ }^{10-12}$. Furthermore, immune checkpoint inhibitors, such as PD-1/PD-L1 axis inhibitors are already in use as anti-cancer therapies ${ }^{13}$. Other immune checkpoint inhibitors, such as IDO1, are still in clinical trials ${ }^{14}$.

This article is protected by copyright. All rights reserved. 
IDO1 is a heme-containing enzyme that controls the immune system through several inhibitory pathways mediated by cell metabolism ${ }^{15}$. An increase in IDO1 expression leads to raised T-cell tolerance and promotes the differentiation of naïve $\mathrm{CD} 4^{+} \mathrm{T}$ cells into regulatory T cells ${ }^{16}$. On the other hand, PD-L1, a ligand for programmed death receptor 1 , can induce immune tolerance by reducing $\mathrm{CD}^{+} \mathrm{T}$ cell proliferation and promoting functional $\mathrm{T}$ cell exhaustion ${ }^{17}$.

There are currently several studies on the immunohistological expression of immune checkpoint molecules in oral cancer ${ }^{11,18}$. However, less is known about the roles of these molecules in potentially malignant oral lesions. Therefore, the purpose of this study was to analyze the expression of IDO1 and PD-L1 in oral dysplasia; to investigate the possible association between these molecules, dysplasia grade, and the inflammatory cell infiltration; and to follow disease progression and the expression of these molecules over time in oral dysplasia samples.

\section{MATERIALS AND METHODS}

\section{Patients and Ethical Approval}

The study plan was approved by the Ethics Committee of the Ostrobothnian Hospital District (46/2013). Sixty-three archival oral dysplasia samples from 47 patients (mean age 60.7 years; median 65 years) treated at the Oulu University Central Hospital through years 2005-2016 were included. Nine of the patients had been diagnosed with epithelial dysplasia with lichenoid features. The remaining patients were clinically diagnosed with leukoplakia, erythroleukoplakia, or erythroplakia. Eight of the patients were followed from 3 to 36 months and more than one biopsy (mostly incisional) was taken from the same site. Nine clinically 
normal alveolar mucosal samples were taken during impacted wisdom tooth extraction from healthy donors (mean age 32.6 years; median 26 years) and were used as healthy controls. Dysplasia samples were diagnosed by two oral pathologists (Fabricio Passador-Santos, and Tuula Salo) according to the WHO classification ${ }^{19}$. Samples were fixed in $10 \%$ neutralbuffered formalin and embedded in paraffin (formalin-fixed, paraffin-embedded samples, FFPE). Absence of pathology was confirmed in the control samples by clinical and histologic examination. Samples were coded to assure anonymity and safeguarded. Detailed patient data are presented in Table 1.

\section{Immunohistochemical Staining:}

FFPE samples were cut to 5- $\mu \mathrm{m}$ thick sections. Immunohistochemical (IHC) staining for IDO1 was performed using a fully automated BOND-MAX staining robot (Leica Microsystems, Wetzlar, Germany) and a horseradish peroxidase-labelled dextran polymer method (Bond Polymer Refine Detection Kit, Leica Microsystems). The machine was supplied with a monoclonal mouse anti-human IDO1 (Cat. No. \#MAB5412; Millipore, Burlington, Massachusetts, USA) at a dilution of 1:200 (working concentration $5 \mu \mathrm{g} / \mathrm{ml}$ ). For PD-L1, antigen retrieval was performed in microwave using abcam Universal HIER antigen retrieval reagent (Cat. No. ab208572; Abcam, Cambridge, United Kingdom). Slides were incubated with rabbit anti-human PD-L1 (Cat. No. ab205921; Abcam) at a dilution of 1:400 (working concentration $2.5 \mu \mathrm{g} / \mathrm{ml}$ ) at room temperature for 1 hour. Staining was performed using Lab Vision Autostainer (Thermo Fisher Scientific, Waltham, Massachusetts, USA) and Dako Advance HRP (Dako, Glostrup, Denmark). Negative controls (without primary antibody) for IDO-1 and PD-L1, and positive control (tonsil tissue) for PD-L1 were done to confirm the quality of the staining (data not shown).

This article is protected by copyright. All rights reserved. 


\section{Evaluation of staining and cell counting}

A fully-automated Leica DM6000 microscope together with a Leica DFC365-FX camera (Leica Microsystems) and a BX61 Motorized System Microscope (Olympus Life and Material Science Europa GmbH, Hamburg, Germany) were used to image the stained samples.

Dysplasia grade was scored by two oral pathologists (Fabricio Passador-Santos, and Tuula Salo) as (1) mild, (2) moderate, or (3) severe (Figure 1A-C). The two pathologists had a moderate agreement on the dysplasia grade $(\mathrm{k}=0.45)$. Unfortunately, oral dysplasia grading had been reported to be poorly reproducible between observers ${ }^{19}$. Fourteen (out of 47) dysplasia samples had both non-dysplastic and dysplastic areas. IDO1 staining intensity in the epithelium and lamina propria and inflammatory cell infiltrate were scored as (0) negative, (1) weak, (2) moderate, or (3) strong. The number of PD-L1 positive cells in the lamina propria were counted from three 20x magnification fields per slide in the areas with the highest numbers of PD-L1 positive cells. Except for the dysplasia grades, all scorings were performed independently by 2 researchers (Meri Sieviläinen and Rabeia Almahmoudi) who were blinded to clinical data and outcomes. An experienced oral pathologist (Fabricio Passador-Santos settled discrepancies in the scoring.

\section{Statistical Analyses}

All statistical analyses were performed using SPSS (IBM SPSS Statistics for windows, version 21.0. Armonk NY, IBM Corp.) Only the initial sample was included in the statistics for each patient. Kappa coefficient test was used to check the agreement between the two pathologists on the dysplasia grades. Non-parametric statistical methods were used due to the small range and categorical nature of the observations. Mann-Whitney U test and Wilcoxon rank-sum tests were used to compare between the study groups. Spearman's rank correlation 
was computed to observe the strength and direction of association among variables. Due to the small number of observations, chi-square tests of association were performed on further categorizing the variables. $P$-values $\leq 0.05$ were considered statistically significant.

\section{Results}

IDO1 expression is downregulated in dysplastic oral epithelium compared with healthy controls

In healthy controls, IDO1 was strongly expressed in all oral epithelial layers except the basal layer (Figure 1D). In the dysplastic oral epithelium, IDO1 was either weakly positive or negative (Figure 1E). This difference was highly significant $(P<0.0001$, Figure 1F). In the lamina propria, IDO1 was similarly expressed in samples from patients with oral dysplasia and healthy controls $(P>0.05$, data not shown). Within the same sample, the epithelium at the dysplastic free area had higher IDO1 expression than that of the dysplastic epithelium $(P=0.004$, Figure $1 \mathrm{G}, \mathrm{H})$.

PD-L1 positive cell count is increased in dysplastic lamina propria compared with healthy controls

PD-L1 was negative in the oral epithelium of both healthy controls and dysplastic samples (Figure 1F-G). On the other hand, PD-L1 was expressed in the lamina propria inflammatory cells of the dysplastic samples and seldom in healthy controls (Figure 1I-K).

This article is protected by copyright. All rights reserved. 


\section{Dysplasia grade is associated with IDO1 and PD-L1 expression levels and the amount of inflammatory cell infiltration}

Dysplasia grade was negatively associated with epithelial IDO1 expression (Supplement A, Table 2) and positively with lamina propria IDO1 (Table 2) and PD-L1 positive cell count (Supplement B, Table 2). Dysplasia grade was also positively associated with inflammatory cell infiltration (Table 2).

\section{IDO1 and PD-L1 expression does not correlate with patient characteristics}

Dysplasia patients were categorized according to their age ( $\leq 50$ and $>50$ years), gender, smoking status, site of the lesion (tongue and others), presence of lichenoid features, and presence of previous cancer. Neither IDO1 nor PD-L1 associated with any of the studied categories, except PD-L1, which was expressed slightly more in the samples which have lichenoid features (Table 2). The presence of lichenoid features associated positively with inflammatory cell infiltration and dysplasia grade. Dysplasia grade was higher in male patients (Table 2).

\section{Dysplasia grade, inflammatory cell infiltration and IDO1 and PD-L1 expression}

\section{fluctuate over time}

Eight patients were followed from 3 to 36 months with more than one biopsy taken. Dysplasia grade, inflammatory cell infiltration, and IDO1 (in both the epithelium and lamina propria) and PD-L1 expression fluctuated over time (Figure 2). No stable progression was detected in any of the studied criteria. 


\section{DISCUSSION}

This study revealed a significant association between oral epithelial dysplasia grade, inflammatory cell infiltration, and expression of immune checkpoint molecules (IDO1 and PD-L1). Interestingly, these associations were either positive or negative depending on the molecules studied and the site of its expression (epithelium or lamina propria). Additionally, dysplasia grade, inflammatory cell infiltration, and expression of immune checkpoint molecules fluctuated over time.

We found that IDO1 is strongly expressed in healthy control epithelium compared with dysplastic lesions. The same phenomenon was present in samples with dysplastic and nondysplastic areas, which supports our previous observation. Even though IDO1 expression is induced in oral cancer ${ }^{5}$, we were surprised to observe the opposite in dysplastic oral epithelium. This could possibly be due to the loss of immune tolerance in the dysplastic oral epithelium ${ }^{20}$, as IDO1 plays an important role in inducing immune tolerance. Immune tolerance is known to be essential in the oral mucosa due to the presence of a large number of different microbes in the oral cavity ${ }^{21,22}$. Loss of immune tolerance could result in activation of the immune system and infiltration of inflammatory cells ${ }^{23}$. Such phenomena are indeed occurring in oral dysplasia as this study found that dysplasia grade was positively associated with inflammatory cell infiltration, even though oral dysplasia is not an infectious disease. On the other hand, IDO1 expression in the lamina propria was enhanced with increase in dysplasia grade, which may be caused by associated inflammation and the production of proinflammatory cytokines ${ }^{24}$.

In contrast to the expression of PD-L1 in cancer cells of oral squamous cell carcinoma ${ }^{25-27}$, in our study PD-L1 was negative in the oral epithelium of both healthy control and dysplasia samples. In the lamina propria, PD-L1 was expressed mainly in dysplastic samples and only 
rarely in controls. We found a significant positive association between PD-L1 expression and dysplasia grade as well as inflammatory cell infiltration. This result is consistent with a recent publication suggesting a positive correlation between PD-L1 expression in oral dysplasia and the risk of malignant transformation ${ }^{28}$. This publication also reported that inflammatory cells, mainly CD163 and CD8, are the major producer of PD-L1 in oral dysplasia tissue. This supports our results where the increase in the PD-L1 positive cells is associated with an increase in inflammatory cell infiltration.

In terms of patient characteristics, it was interesting to notice that almost none of the studied immune checkpoints yielded significant correlations. As an exception, however, PD-L1 was positively associated with the presence of lichenoid features. This phenomenon may reflect the presence of severe inflammatory cell infiltration associated with lichenoid features. Regarding dysplasia grade, it was positively associated with the presence of lichenoid features. This observation should be interpreted with caution, as most of the studied cases were clinically suspicious for cancer. In our samples, male patients had on average a higher oral dysplasia grade, which is associated with a greater risk for malignant transformation. In contrast, studies on other populations have shown that dysplasia in females more often transform to cancer ${ }^{29}$. The explanation for our finding could be due to several factors, including hormones and male lifestyle, such as smoking. Although $40 \%$ of males and only $10 \%$ of the females were smokers (data not shown), we did not find any association between dysplasia grade and smoking. Further studies are needed to reveal the connection between gender and dysplasia grade.

We followed the disease progression of eight patients over different periods. In contrast to our hypothesis of progression in dysplasia grade and other analyzed parameters, no such pattern was detected. Instead, all studied parameters fluctuated over time. This result is 
consistent with previous observations that the progression of dysplasia in oral cavity might not be linear ${ }^{30}$.

In conclusion, the present study demonstrated that the expression of IDO1 and PD-L1 are associated with the dysplasia grade and with inflammatory cell infiltration, which putatively indicates that these immune checkpoints might have a role in the progression of dysplasia. As this is an exploratory study, we have tried to look at many possible associations in the data. However, further specific studies are required to confirm any associations presented from the present study. The findings of the time-series samples suggest that the progression pattern of dysplasia is not a liner process. Accordingly, the patients should be carefully followed regardless of the dysplasia grade.

\section{ACKNOWLEDGMENTS}

The authors acknowledge Ms. Leena Saikko for performing immunohistochemical staining.

\section{REFERENCES}

1. Izumo T. Oral premalignant lesions: from the pathological viewpoint. Int J Clin Oncol. 2011 Feb;16(1):15-26.

2. Shariff JA, Zavras AI. Malignant transformation rate in patients presenting oral epithelial dysplasia: systematic review and meta-analysis. J Oral Dis. 2015;2015.

3. Bradley G, Odell EW, Raphael S, Ho J, Le LW, Benchimol S, et al. Abnormal DNA content in oral epithelial dysplasia is associated with increased risk of progression to carcinoma. Br J Cancer. 2010;103(9):1432-42.

This article is protected by copyright. All rights reserved. 
4. Ho MW, Risk JM, Woolgar JA, Field EA, Field JK, Steele JC, et al. The clinical determinants of malignant transformation in oral epithelial dysplasia. Oral Oncol. 2012;48(10):969-76.

5. Liu W, Bao Z, Shi L, Tang G, Zhou Z. Malignant transformation of oral epithelial dysplasia: clinicopathological risk factors and outcome analysis in a retrospective cohort of 138 cases. Histopathology. 2011;59(4):733-40.

6. Laimer K, Troester B, Kloss F, Schafer G, Obrist P, Perathoner A, et al. Expression and prognostic impact of indoleamine 2,3-dioxygenase in oral squamous cell carcinomas. Oral Oncol. 2011;47(5):352-7.

7. Conway C, Graham JL, Chengot P, Daly C, Chalkley R, Ross L, et al. Elucidating drivers of oral epithelial dysplasia formation and malignant transformation to cancer using RNAseq. Oncotarget. 2015;6(37):40186.

8. Topalian SL. Targeting Immune Checkpoints in Cancer Therapy. Jama. 2017;318(17):1647-8

9. Mittal D, Gubin MM, Schreiber RD, Smyth MJ. New insights into cancer immunoediting and its three component phases_elimination, equilibrium and escape. Curr Opin Immunol. 2014;27:16-25.

10. Lucarelli G, Rutigliano M, Ferro M, Giglio A, Intini A, Triggiano F, et al. Activation of the kynurenine pathway predicts poor outcome in patients with clear cell renal cell carcinoma. In: Urologic Oncology: Seminars and Original Investigations. Elsevier; 2017.

11. Seppälä M, Halme E, Tiilikainen L, Luukkainen A, Laranne J, Rautiainen M, et al. The expression and prognostic relevance of indoleamine 2, 3-dioxygenase in tongue 
squamous cell carcinoma. Acta Otolaryngol. 2016;136(7):729-35.

12. Wu P, Wu D, Li L, Chai Y, Huang J. PD-L1 and survival in solid tumors: a metaanalysis. PLoS One. 2015;10(6):e0131403.

13. Ran X, Yang K. inhibitors of the PD-1/PD-L1 axis for the treatment of head and neck cancer: current status and future perspectives. Drug Des Devel Ther. 2017;11:2007.

14. Topalian SL, Drake CG, Pardoll DM. Immune checkpoint blockade: a common denominator approach to cancer therapy. Cancer Cell. 2015;27(4):450-61.

15. Liu X, Shin N, Koblish HK, Yang G, Wang Q, Wang K, et al. Selective inhibition of IDO1 effectively regulates mediators of antitumor immunity. Blood. 2010;115(17):3520-30.

16. Fallarino F, Grohmann U, You S, McGrath BC, Cavener DR, Vacca C, et al. The combined effects of tryptophan starvation and tryptophan catabolites down-regulate $\mathrm{T}$ cell receptor $\zeta$-chain and induce a regulatory phenotype in naive T cells. J Immunol. 2006;176(11):6752-61.

17. Patel SP, Kurzrock R. PD-L1 expression as a predictive biomarker in cancer immunotherapy. Mol Cancer Ther. 2015;14(4):847-56.

18. Kouketsu A, Sato I, Oikawa M, Shimizu Y, Saito H, Takahashi T, et al. Expression of immunoregulatory molecules PD-L1 and PD-1 in oral cancer and precancerous lesions: A cohort study of Japanese patients. J Cranio-Maxillofacial Surg. 2017;

19. El-Naggar A, Chan J, Grandis J, Takata T, Slootweg P, editors. Tumours of the oral cavity and mobile tongue. In: WHO classification of tumours of the head and neck. 4th ed. Lyon: IARC Press; 2017. p. 112-5.

This article is protected by copyright. All rights reserved. 
20. Sun Y, Liu N, Guan X, Wu H, Sun Z, Zeng H. Immunosuppression Induced by Chronic Inflammation and the Progression to Oral Squamous Cell Carcinoma. Mediators Inflamm. 2016;2016.

21. Grohmann U, Puccetti P. The coevolution of IDO1 and AhR in the emergence of regulatory T-cells in mammals. Front Immunol. 2015;6.

22. Mondanelli G, Bianchi R, Pallotta MT, Orabona C, Albini E, Iacono A, et al. A relay pathway between arginine and tryptophan metabolism confers immunosuppressive properties on dendritic cells. Immunity. 2017;46(2):233-44.

23. Oppenheim JJ, Yang D, Biragyn A, Howard OMZ, Plotz P. Chemokine receptors on dendritic cells promote autoimmune reactions. Arthritis Res Ther. 2002;4(S3):S183.

24. Robinson CM, Hale PT, Carlin JM. The role of IFN- $\gamma$ and TNF- $\alpha$-responsive regulatory elements in the synergistic induction of indoleamine dioxygenase. J Interf cytokine Res. 2005;25(1):20-30.

25. Hanna GJ, Woo S-B, Li YY, Barletta JA, Hammerman PS, Lorch JH. Tumor PD-L1 expression is associated with improved survival and lower recurrence risk in young women with oral cavity squamous cell carcinoma. Int J Oral Maxillofac Surg. 2017;

26. Mattox AK, Lee J, Westra WH, Pierce RH, Ghossein R, Faquin WC, et al. PD-1 expression in head and neck squamous cell carcinomas derives primarily from functionally anergic CD4+ TILs in the presence of PD-L1+ TAMs. Cancer Res. 2017;77(22):6365-74.

27. Stasikowska-Kanicka O, Wągrowska-Danilewicz M, Danilewicz M. Immunohistochemical Analysis of Foxp3+, CD4+, CD8+ Cell Infiltrates and PD-L1 in Oral Squamous Cell Carcinoma. Pathol Oncol Res. 2017;1-9.

This article is protected by copyright. All rights reserved. 
28. Yagyuu T, Hatakeyama K, Imada M, Kurihara M, Matsusue Y, Yamamoto K, et al. Programmed death ligand 1 (PD-L1) expression and tumor microenvironment: Implications for patients with oral precancerous lesions. Oral Oncol. 2017;68:36-43.

29. Warnakulasuriya S, Ariyawardana A. Malignant transformation of oral leukoplakia: a systematic review of observational studies. J Oral Pathol Med. 2016;45(3):155-66.

30. Thomson P. Oral precancer: diagnosis and management of potentially malignant disorders. John Wiley \& Sons; 2012.

\section{FIGURE LEGENDS}

Figure 1. Significant decrease of IDO1 and increase of PD-L1 expression in the dysplastic samples compared with the healthy control. HE staining of the oral mucosa showing mild (A), moderate (B) and severe dysplasia (C). Healthy and dysplastic samples were immunostained for IDO1 and PD-L1. Healthy control epithelium was positive for IDO1 (D) while dysplastic epithelium was negative (E). IDO1 expression was significantly lower in the dysplastic epithelium than that in the healthy control (F). Eighteen samples showed both dysplastic and non-dysplastic areas in the same slide (G). For these cases, IDO1 expression was significantly higher in the non-dysplastic areas compared with the dysplastic areas $(\mathrm{H})$. PD-L1 was negative in the epithelium and lamina propria of healthy control samples (I). In dysplastic samples, PD-L1 was negative in the oral epithelium and positive in the lamina propria $(\mathrm{J}, \mathrm{K})$. Scale bar $=100 \mu \mathrm{m} . * * p \leq 0.01, * * * * p \leq 0.0001$

Figure 2. Fluctuation of dysplasia grade, inflammatory cell infiltration, and immune checkpoint expression over time. Eight of the studied patients were followed over different time intervals. The dysplasia grade (A), inflammatory cell infiltration (B), epithelium IDO1 
expression (C), lamina propria IDO1 expression (D), and PD-L1 positive cell count (E) fluctuated over time. Each patient is presented in different colors.

\section{Supplement. Dysplasia grade is negatively associated with epithelium IDO1 expression} and positively associated with lamina propria PD-L1 ${ }^{+}$cell count. Expression of IDO1 in the oral epithelium is negatively associated with dysplasia grade (A). A positive association is observed between the number of the PD-L1 positive cells at the lamina propria and dysplasia grade $(\mathrm{B}) . * p \leq 0.05, * * p \leq 0.01$.

\section{TABLE LEGENDS}

Table 1. Baseline characteristics of patients and healthy controls.

Table 2. Association between dysplasia grade, inflammatory cell infiltration, IDO1 and PDL1 expression, and patient characteristics. Spearman's rank correlation was computed to observe the strength and direction of association among variables. Patient characteristics comparisons were done using Chi-square test.

This article is protected by copyright. All rights reserved. 
Table 1. Baseline characteristics of patients and healthy controls

\begin{tabular}{|c|c|c|c|c|}
\hline \multirow[b]{2}{*}{ Characteristics } & \multicolumn{2}{|c|}{ Patients } & \multicolumn{2}{|c|}{ Control } \\
\hline & No. & (\%) & No. & (\%) \\
\hline \multicolumn{5}{|l|}{ Sex } \\
\hline Male & 22 & $(46.8)$ & 4 & (44) \\
\hline Female & 25 & $(53.2)$ & 5 & $(56)$ \\
\hline \multicolumn{5}{|l|}{ Age (v) } \\
\hline$\leq 50$ & 13 & $(27.7)$ & 2 & (22) \\
\hline$>50$ & 34 & $(72.3)$ & 7 & (78) \\
\hline Smoking & & & NA & \\
\hline Smoker & 14 & $(29.8)$ & & \\
\hline Non-smoker & 33 & $(70.2)$ & & \\
\hline \multicolumn{5}{|l|}{ EDLF* } \\
\hline Yes & 9 & $(19.1)$ & 0 & (0) \\
\hline No & 38 & $(80.9)$ & 9 & $(100)$ \\
\hline \multicolumn{5}{|l|}{ Site of biopsy } \\
\hline Tongue & 35 & $(74.5)$ & & \\
\hline Buccal/labial gingiva & 8 & (17) & & \\
\hline Palate & 2 & (4.3) & & \\
\hline Floor of the mouth & 2 & $(4.3)$ & & \\
\hline Alveolar mucosa & 0 & (0) & 9 & (100) \\
\hline \multicolumn{5}{|l|}{ Previous Cancer } \\
\hline All Cancers & 18 & $(38.3)$ & 0 & (0) \\
\hline Oral squamous cell carcinoma & 16 & (34) & & \\
\hline Oropharyngeal cancer & 1 & $(2.1)$ & & \\
\hline Melanoma & 1 & (2.1) & & \\
\hline Urinary bladder cancer & 1 & $(2.1)$ & & \\
\hline Grade of Dysplasia & & & NA & \\
\hline Mild & 18 & $(38.3)$ & & \\
\hline Moderate & 18 & $(38.3)$ & & \\
\hline Severe & 11 & $(23.4)$ & & \\
\hline
\end{tabular}

This article is protected by copyright. All rights reserved. 
Table 2: Association between dysplasia grade, inflammatory cell infiltration, IDO1 and PD-L1 expression, and patient characteristics. Spearman's rank correlation was computed to observe the strength and direction of association among variables. Patient characteristics comparisons were done using Chi-square test.

\begin{tabular}{|c|c|c|c|c|c|c|c|c|c|c|c|}
\hline & $\begin{array}{l}\text { Dysplasia } \\
\text { grade } \\
r^{*} ; p^{*}\end{array}$ & $\begin{array}{l}\text { Inflammatory } \\
\text { cell infiltration } \\
\mathrm{r} ; \mathrm{p}\end{array}$ & $\begin{array}{l}\text { Epithelial } \\
\text { IDO1 } \\
r ; p\end{array}$ & $\begin{array}{l}\text { LP }^{\#} \\
\text { IDO1 } \\
\text { r;p } \\
\end{array}$ & $\begin{array}{l}\text { LP } \\
\text { PDL-1 } \\
r ; p\end{array}$ & \begin{tabular}{|l|} 
Age \\
(50 or $<$ ) \\
$p$
\end{tabular} & $\begin{array}{l}\text { Smoking } \\
\mathrm{p}\end{array}$ & $\begin{array}{l}\text { Previous } \\
\text { cancer } \\
\text { p }\end{array}$ & $\begin{array}{l}\text { EDLF }^{\# \#} \\
p\end{array}$ & $\begin{array}{l}\text { Gender } \\
\text { (Male) } \\
p\end{array}$ & $\begin{array}{l}\text { Site } \\
\text { (Tongue) } \\
p\end{array}$ \\
\hline $\begin{array}{l}\text { Dysplasia } \\
\text { grade }\end{array}$ & & $0.4 ; 0.003$ & $-0.3 ; 0.05$ & $0.3 ; 0.01$ & $0.4 ; 0.005$ & 0.4 & 0.2 & 0.7 & 0.03 & 0.01 & 0.7 \\
\hline $\begin{array}{l}\text { Inflammatory } \\
\text { cell infiltration }\end{array}$ & $0.4 ; 0.003$ & & $-0.2 ; 0.2$ & $0.1 ; 0.5$ & $\begin{array}{l}0.6 ; \\
<0.0001\end{array}$ & 0.9 & 0.4 & 0.6 & 0.03 & 0.2 & 0.2 \\
\hline $\begin{array}{l}\text { Epithelial } \\
\text { IDO1 }\end{array}$ & $-0.3 ; 0.05$ & $-0.2 ; 0.2$ & & $0.05 ; 0.8$ & $-0.2 ; 0.3$ & 0.09 & 0.6 & 0.8 & 0.7 & 0.3 & 0.9 \\
\hline $\begin{array}{l}\text { LP } \\
\text { IDO1 }\end{array}$ & $0.3 ; 0.01$ & $0.1 ; 0.5$ & $0.05 ; 0.8$ & & $0.1 ; 0.5$ & 0.6 & 0.3 & 0.4 & 0.5 & 0.1 & 0.3 \\
\hline $\begin{array}{l}\text { LP } \\
\text { PDL-1 }\end{array}$ & $0.4 ; 0.005$ & $0.6 ;<0.0001$ & $-0.2 ; 0.3$ & $0.1 ; 0.5$ & & 0.5 & 0.06 & 0.9 & 0.05 & 0.6 & 0.1 \\
\hline
\end{tabular}

\footnotetext{
${ }^{*} r=$ correlation coefficient

** $p=$ calculated probability

"LP = Lamina propria

"\#EDLF = Epithelial dysplasia with lichenoid features

Statistically significant correlations are marked with bold.
} 


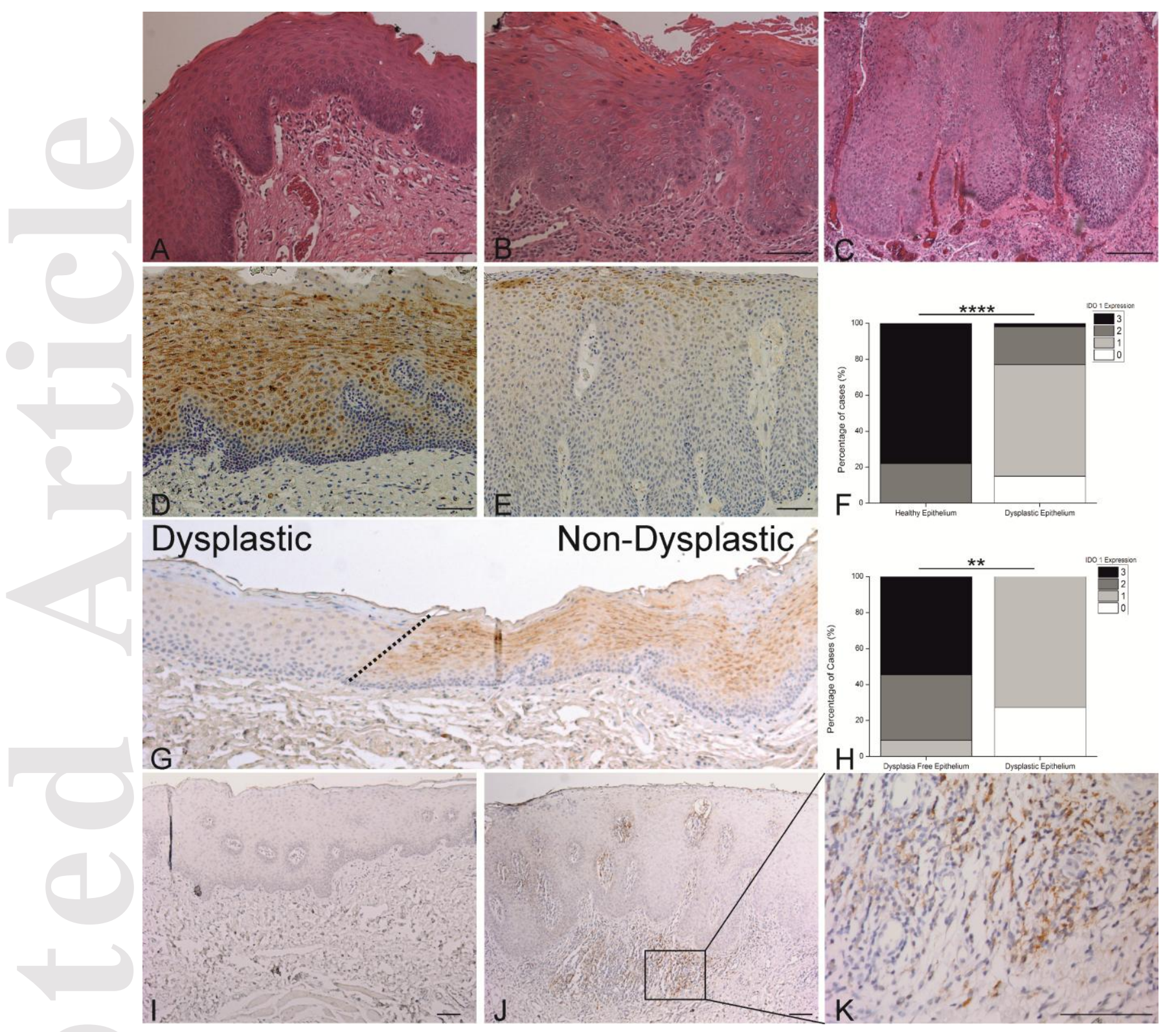

This article is protected by copyright. All rights reserved. 

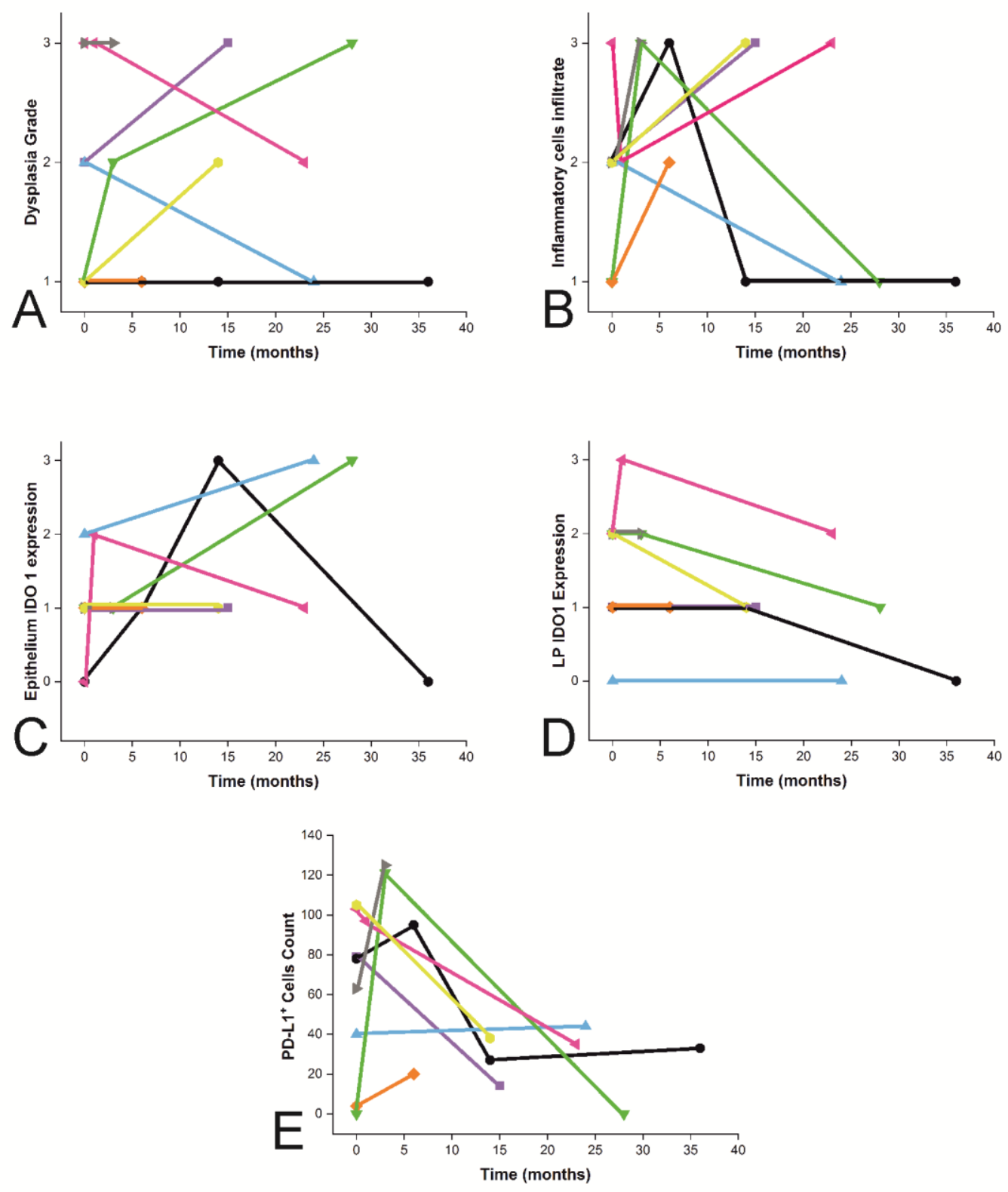

This article is protected by copyright. All rights reserved. 